\title{
La retórica de la ciencia y el estudio de las diferencias sexuales ${ }^{1}$
}

\author{
Eulalia Pérez Sedeño
}

L

os denominados estudios sobre ciencia y género abarcan diversas áreas y cuestiones, y están cobrando importancia a pasos agigantados. Figuras olvidadas y aspectos de la historia de la ciencia hasta ahora no tenidos en cuenta, estrategias ideadas para aumentar la presencia de las mujeres en la ciencia y críticas a las supuestas caracteristicas fundamentales de ella, han sido objeto de análisis y estudio desde perspectivas diferentes. ${ }^{2}$

Uno de los aspectos más desarrollados ha sido la crítica a los supuestos ideológicos de determinadas disciplinas que han posibilitado y justificado la situación de inferioridad de las mujeres a lo largo de la historia. Eso ha sido posible, en parte, gracias a la "retórica de la ciencia"3 que ha conseguido, a

Una primera versión de este trabajo fue presentado en el I Congreso Multidisciplinar "Ciencia y Género", Madrid, 29-31 de mayo de 1996. El trabajo en que se basa ha sido financiado en parte por la CICrT, proyecto PB95-0125-C06-03.

2 Para un panorama del desarrollo de todas estas subáreas véase, por ejemplo, Eulalia Pérez Sedeño, "De la biología imaginaria a la sociología real" en García de Cortázar et al., 1995 y "Filosofia de la ciencia y feminismo: intersección y convergencia", en Isegoría, vol. 12, 1995.

${ }^{3}$ En los últimos años se ha hablado de la intersección, o de la unión, según los casos, entre ciencia y retórica o, dicho de otro modo, del nuevo giro retórico. Las muchas variaciones por lo que respecta a la estimación de la importancia de la retórica en la ciencia van desde quienes afirman que el discurso científico, como cualquier otro, incorpora elementos retóricos, es decir, la retórica es la envoltura del discurso científico y el tener en cuenta esto hace necesario replantearse y elaborar una nueva imagen de la ciencia (por ejemplo H. H. Bauer, Scientific Literacy and the Myth of Scientific Method. Urbana, Universidad de Illinois, 1992 y S. Fuller, Philosophy, Rhetoric and the End of Knowledge. Madison, Universidad de Wisconsin, 1993), hasta quienes mantienen que la retórica es parte esencial constitutiva de la ciencia (por ejemplo A. G. Gross, The Rhetoric of Science. Cambridge, Universidad de Harvard, 1990). 
través del denominado "método científico", la construcción retórica más eficaz de todas: la historia, la sociología y ciertas filosofias de la ciencia muestran que ciencia no equivale a racionalidad, objetividad y neutralidad, pero la retórica de la ciencia ha conseguido que así se considere. En este trabajo pretendo presentar algunos ejemplos del excelente funcionamiento retórico de la ciencia en el estudio "científico" -es decir, neutro, objetivo y racional- del sexo o, más exactamente, de las diferencias sexuales.

Los recursos retóricos utilizados en el tratamiento del sexo han variado a lo largo de la historia, aunque permanecen algunas constantes. La más importante parece ser común a distintas "teorias" biológicas y consiste en presentar como sexuales, es decir, biológicas, naturales, las diferencias de género, esto es, históricas, culturales. ${ }^{4}$ Se utiliza la "biología" como tribunal supremo al que se apela en última instancia. Su retórica de la objetividad y la neutralidad sirve para justificar situaciones sociopolíticas. Se intenta convencer, persuadir ${ }^{5}$ de que la naturaleza de la mujer la condiciona en sus papeles socioculturales situándola en un estatus de inferioridad que debe seguir manteniendo, aunque para ello sea necesario recurrir a argumentos lógica y metodológicamente no legítimos, según los principios de los propios autores y a valoraciones no neutrales. A la vez, la premisa de que se parte es la propia situación sociopolítica, histórica, contextual, que se quie. re justificar, para hacer afirmaciones biológicas, cerrándose así el círculo.

${ }^{4}$ Utilizo aqui la distinción clásica entre sexo y género, presentada por Ann Oakley en su obra Sex, Gender and Society (1972). Sexo refiere a las diferencias fisiológicas más básicas entre hombres y mujeres, es decir, genitales y reproductivas (por lo general, al hablar de diferencias sexuales se habla de "macho" y "hembra", categorias éstas que se aplican a casi todo el reino animal). Género, en cambio, refiere a pautas de comportamiento, culturalmente específicas, ya sean reales o normativas, y que se pueden aplicar a los sexos "en este caso las categorías que se usan son "masculino" y "femenino" y su aplicación a individuos de otras especies animales es escasa, por no decir nula. Mientras que el contenido de la distinción "macho/hembra" estaria genéticamente determinado, el contenido de la distinción "masculino/femenino" estaría culturalmente determinado y seria variable.

${ }^{5}$ La idea o definición de retórica ha cambiado a lo largo de los siglos. Unas veces se ha considerado que es un "arte" que se ocupa del lenguaje o de los argumentos, otras veces de las pasiones expresadas por el lenguaje, de los efectos producidos por las composiciones "retóricas", de las relaciones entre esas composiciones y conceptos abstractos como "verdad", "justicia", etcétera. Pero sea cual sea la definición adoptada siempre se ha aplicado a cómo se usa el lenguaje (o tipos del lenguaje) para conmover, agradar o persuadir al oyente o lector con respecto a juicios especificos, decisiones o acciones. Como dice el Diccionario de la Real Academia Española, la retórica es "el arte del bien decir, de embellecer la expresión de los conceptos, de dar al lenguaje escrito o hablado eficacia bastante para deleitar, persuadir o conmover". 
A menudo se opone naturaleza a cultura. Cuando tal oposición se aplica a la mujer, se hace para afirmar que su naturaleza la condiciona en sus papeles socioculturales. Es decir, cuando se habla de la "naturaleza de la mujer" (o de su "determinación biológica") no se está acotando simplemente un problema científico, de manera neutra y objetiva, el de los mecanismos reproductivos, sino de qué manera esos mecanismos reproductivos repercuten en el comportamiento en general, dando por sentado que tal "hecho biológico" se plasma en la capacidad intelectual, la conducta social y psicológica de la mujer ${ }^{6} \mathrm{y}$, por consiguiente, en el papel que la sociedad le asigna.

El recurso a la "naturaleza" de la mujer para defender las limitaciones intelectuales y sociopolíticas que se le han impuesto ha tenido múltiples defensores, aunque también detractores, a lo largo de la historia. Aristóteles fue el primero en dar una "explicación" biológica y sistemática de la mujer, en la que ésta aparece como un hombre imperfecto, justificando así el papel subordinado que social y moralmente debían desempeñar las mujeres en la polis. La imperfección viene dada, sobre todo, por el supuesto, incuestionable para Aristóteles, de que la forma propia u original de la humanidad es mascu$\operatorname{lina}^{7}$ y por el principio de que lo que permite que los animales se desarrollen es el calor, que es fundamental para la perfección de los animales: "Lo que por naturaleza tiene menor proporción de calor es más débil". 8

La frialdad de la mujer le permite explicar numerosas supuestas diferencias fisiológicas y psicológicas entre la mujer y el hombre; csto no sería nada extraño si no fuera porque las características diferenciales de la mujer son calificadas de defectos, son consideradas inferiores, introduciendo, pues, valores no cognoscitivos. Debido a que la mujer posee menos calor, es menor y más débil que el hombre. "El macho es mayor y vive más tiempo que la hembra $[. .$.$] la hembra es menos musculosa y menos compacta". { }^{9}$ La deficiencia en calor de la mujer hace que su cerebro sea menor y esté menos de. sarrollado; y el menor tamaño de su cerebro es la causa de otros muchos defectos. La mujer es "más celosa, más quejumbrosa, más apta para regañar y golpear. Ella es, además, más propensa al desaliento y menos optimista que el hombre, tiene menos vergüenza, es más falsa en el habla, más engañosa y de memoria más retentiva". ${ }^{10}$ De la deficiencia "natural", "biológica", se salta a cualidades moralmente negativas. Pero además, si nos preguntamos en qué

${ }^{6} \mathrm{Y}$ sólo de la mujer, pues para el varón no parece haber tal condicionamiento biológico.

${ }^{7}$ Principio que ya aparece en las cosmologías de Hesíodo y Platón.

${ }^{8}$ Aristóteles Sobre la generación de los animales, 726.b.33.

${ }^{9}$ Aristóteles, Historia de los animales, 538.a.23-b.8.

${ }^{10}$ Ibid., 608.b.10-12. 
se basa Aristóteles para afirmar la frialdad de la mujer con respecto al varón nos llevaremos una sorpresa. Pues explicaba que el defecto innato de calor en la mujer se debe a que un embrión se convierte en hembra "cuando el primer principio no domina y no puede cocer el nutriente por falta de calor ni darle su forma adecuada". " Claro que esa no es una explicación de la causa del defecto de la mujer, sino una afirmación de éste. En primer lugar, y sin aducir prueba alguna Aristóteles se adhiere al principio de que la "forma adecuada" de un ser humano es la de varón, ${ }^{12}$ por lo que, la mujer no es completamente humana. Al mantener que la naturaleza siempre pretende crear el ser más perfectamente formado - un macho, dado el punto de partida anterior- está claro que el embrión femenino surge de la desviación de la naturaleza, por lo que Aristóteles concluía que la hembra tenía que ser el resultado de o bien falta de calor generador o de alguna adversidad, cerrando el círculo de nuevo.

Las fintas que tiene que realizar Aristóteles para justificar la imperfección de la mujer y, por ende, su estatus inferior, se aprecian claramente cuando habla del defecto de calor como causa de dicha imperfección y de su papel en la reproducción: "La hembra es, como si dijéramos, un macho mutila. do". 13 Sin embargo, al observar que nacian más varones con defectos que mujeres, no concluyó, como pareceria lógico, que eso se debiera a un defecto de calor, pues eso iría en contra de la premisa de la superioridad fisiológica del varón. Aristóteles mantenía que, debido al mayor calor narural del macho, el feto macho "se mueve más que el feto hembra y debido a su movimiento es más susceptible de herirse" ${ }^{\prime \prime}{ }^{14}$ insistiendo en que los defectos de nacimiento de los varones no se deben a la falta de calor, sino a su superioridad en este aspecto.

La valoración no cognoscitiva de las cualiuades "naturales" se aprecia perfectamente una vez más cuando intenta explicar por qué la mujer comienza antes la pubertad. Aristóteles afirma que el desarrollo acelerado es señal de un calor superior, razón de que los fetos machos se movieran antes que los fetos hembras. Pero al trazar una distinción sin fundamento entre

"Ibid., 766.a.18-20.

12 Interpretar que Aristóteles afirma que sólo los varones son completamente humanos es exacto, pero sería un error inferir que también apoyaba la postura de que todos los varones son completamente humanos. Consideraba que los esclavos varones no poseían facultad deliberadora y, por tanto, estaban lejos de ser plenamente humanos. Aunque reconocía que la inferior condición de ser esclavo no es natural, pues se puede "adquirir" en guerras, conquistas, etcétera, no parece que hiciera una consideración análoga con respecto a las mujeres. Véase Política, 1260.a.12-14.

13 Aristóteles, Sobre la generación de los animales, 737.a.27.28.

${ }^{14}$ Ibid., $775 . a .6-7$. 
desarrollo prenatal y posnatal, Aristóteles apuntó al momento del comienzo de la pubertad como prueba adicional de la imperfección de la mujer.

Pues las hembras son más débiles y frías por naturaleza, y debemos considerar que el carácter de la hembra es una especie de deficiencia natural. En consecuencia, mientras se halla dentro de la madre, se desarrolla lentamente debido a su frialdad (pues el desarrollo es cocción y lo que cuece es el calor y lo que está más caliente se cuece con mayor facilidad). Pero después del nacimiento llega rápidamente a la madurez y a la vejez a causa de su debilidad, pues todas las cosas inferiores llegan antes a su perfección, y así como esto es cierto de las obras de arte, también lo es de lo que se forma en la naturaleza. ${ }^{15}$

Aristóteles reforzó su teoría argumentando que el defecto de calor de la mujer es necesario para la reproducción, vinculando, así, naturaleza de la mujer, imperfección e inferioridad. Sólo un ser incapaz de cocer la materia completamente sería capaz de nutrir un feto. El macho, capaz de cocer toda su materia, no tendría residuos para alimentar al feto en crecimiento. Así, el papel de la mujer en la generación está unido a su imperfección. Aristóteles concluyó que, aunque la mujer es un macho mutilado, su mutilación es nece. saria para perpetuar la raza. ${ }^{16} \mathrm{La}$ mujer es menos perfecta que el hombre, pero su imperfección es "natural".

La biología de Aristóteles, que era más bien un conglomerado de supuestos ideológicos, sirvió de apoyo a los defensores de la supuesta inferioridad de la mujer a lo largo de los siglos. La biología aristotélica, remozada por Galeno, sirvió de base a quienes abogaban porque las mujeres desempeñaran solamente el papel de reproductoras de la especie y sumisas esposas recluidas en la esfera privada sin papel alguno en la esfera pública y negándoles hasta un elemental derecho a la educación. ${ }^{17}$ Por ejemplo, el padre Male. branche mantenía que los cuerpos suaves y débiles de las mujeres constituyen un espejo preciso de la suavidad, blandura y consistencia que conforma sus cerebros. David Avercromby, el célebre médico del siglo xvil, no mantenía opiniones muy diferentes: "la mujer no ha recibido de Dios alma tan perfecta como la del hombre, porque por orden especial de Dios ellas deben obedecer y los hombres mandar. La falta de capacidad mental conforma todo esto: sus procesos de pensamiento son zafios y son incapaces de selección o

15 Ibid., 775.a.14-21. Subrayado mío.

${ }^{16}$ Ibid., 737.a.27.28.

${ }^{17}$ Sobre el debate acerca de la educación de la mujer, véase E. Pérez Sedeño y A. Gómez, eds., "El sexo de la ciencia". (En prensa.) 
discernimiento". ${ }^{18}$ Una manera habitual de apoyar empíricamente las afirmaciones de incapacidad intelectual consistía, por cierto, en examinar el cuarto de la mujer; éste, se consideraba espejo del alma, reflejo de la mente, y los resultados de su examen eran los esperados: botes de mermelada, libro de oraciones, afeites... todo confuso y desordenado. Y en el mismo sentido se manifiestan pensadores españoles como Fray Luis de León o el doctor Huarte de San Juan; según éste, las mujeres son frías y húmedas y los hombres secos y calientes; la humedad y el frío echan a perder la parte racional, mientras que el calor y la sequedad -iqué casualidad!- la aumentan y perfeccionan. Puede que haya alguna mujer con algo de ingenio y habilidad, pero eso indicaría que tiene cualidades masculinas, es decir, calor y sequedad, aunque en grado muy bajo, porque si las tuviera en mayor cantidad habria nacido hombre. Como apoyo empírico de su teoría muestra un dato fundamental: Eva, la primera mujer, no mostró mucha inteligencia en el Paraíso (aunque, Adán tampoco demostró muchas luces).

En muchos casos las razones aducidas por los varones, contrarios a la educación de la mujer, eran la amenaza que ello suponía para el orden establecido del hogar. Tal es el caso de Agrippa d'Aubigne, quien decía que el estudio "engendraba laxitud en las tareas domésticas y discordia en los matrimonios". ${ }^{9}$ Por lo general, se recomendaba que las mujeres recibieran la menor educación posible: "Respecto a las humildes, no es necesario que sepan leer; respecto a las de mediana condición, no les enseñen a leer; respecto a las mujeres de la nobleza que deben ser madres de familias numerosas, apruebo que aprendan a leer un poco (mediocremente) y que aprendan un poco de matemáticas". ${ }^{20}$ Por ejemplo, a Hana More (1745-1833) le prohibieron seguir estudiando porque su aptitud para el latín y las matemáticas era demasiado elevada para una mujer. Pero incluso quienes aceptaban la enseñanza a las mujeres no consideraban que sus conocimientos debieran ser públicos. Fenelón, en su Tratado sobre la educación de las niñas (1687) aceptaba que se enseñara latín a las niñas de "inteligencia excepcional" pero sólo las que "no estuviesen tentadas por la curiosidad vana sabrian disimular lo que habian aprendido y lo utilizarian para su propio beneficio". Thomas Moro aconsejaba a su hija que limitara su audiencia a sí mismo y a su marido. Y muchas décadas después, lady Montagu aconsejaba a su hija que permitiera a su nieta leer los Principia Mathematica de Newton, pues no se sabía de ninguna mujer que se hubiera vuelto más vana y cretina por leer tal

${ }^{18}$ Citado en P. Phillips, The Scientific Lady, Londres, Weidenfeld and Nicolson, 1990, p. 45

${ }^{19}$ Citado en M. King, Mujeres renacentistas. Madrid, Alianza, 1993, p. 237.

${ }^{20}$ Sulvio Antoniano, pedagogo del siglo XVI. 
obra, a no ser que ya lo fuera, aunque, eso si, le aconsejaba que no diera publicidad a tal lectura.

En los siglos XVIII y xIX, la biología comenzó la búsqueda de las diferencias sexuales con los métodos de la ciencia moderna. El debate sobre la capacidad y los derechos de la mujer se planteó, al parecer, de una manera distinta, dado que supuestamente había probado su objetividad y neutralidad, empíricamente basada, así como su efectividad para el progreso social y tecnológico. A partir de entonces, las afirmaciones sobre la inferioridad de la mujer se basan en las diferencias biologicas o naturales entre mujeres y hombres de tres maneras distintas. Por un lado, algunos, apoyándose en la teoría científica de la conservación de la energía, han mantenido su veto a la educación superior de la mujer: el esfuerzo que habrían de dedicar a su instrucción les quitaría una energía necesaria para el funcionamiento correcto de sus funciones menstruales y reproductivas, lo que les impediría su objetivo primordial, ser madres, ya que decían que con el estudio aumenta el cerebro y, al aumentar éste, disminuyen los ovarios. ${ }^{21}$ Por otro lado, los anatomistas se dedicaron a describir las diferencias entre hombre y mujer basándose en las diferentes dimensiones del cráneo y del cerebro para afirmar que un menor tamaño indicaba una menor capacidad, por lo que de nada servirian las campañas en favor de la educación superior de la mujer, pues ésta nunca llegaría a alcanzar al hombre en ese aspecto. ${ }^{22}$ Por último, a finales del siglo xIx, los darwinistas sociales proclamaron que la mujer era un hombre que, ni física ni mentalmente, había evolucionado completamente. 23

Una de las teorias "de la naturaleza" utilizadas para convencer de la inferioridad intelectual y social de la mujer fue la teoría de la evolución. Convencido como estaba de la diferencia mental entre los dos sexos, del sometimiento del sexo "débil" al fuerte ${ }^{24}$ y de la existencia de un continuo moral entre los

${ }^{21}$ Por ejemplo, H. Maudesley. No obstante, en esa misma década, M. P. Jacobi argumentaba con datos en la mano que esa tesis no se sostenia, puesto que había mujeres instruidas que tenían hijos.

${ }^{22}$ Pero otros, como J. M. Allan, contraargumentaban que si el tamaño menor del cerebro de las mujeres era efecto de su inferioridad social, si las mujeres pudieran desarrollar plenamente sus cerebros se remediaria ese efecto pernicioso. El hecho de que las mujeres lograran efectivamente el acceso a la educación superior y alcanzaran intelectualmente al varón, convirtió en inaceptables las tesis y medidas de los crancólogos, que implicaban que eso era imposible (véase W. L. Distant, "On the Mental Differences Between the Sexes", en Journal of the Royal Anthropological Institute of Great Britain and Ireland, núm. 4, 1874, pp. 78-87).

${ }^{23}$ Véase A. Gómez et al., "Ciencia y retórica: una bibliografia reciente", en Isegoría, núm. 12, 1995, pp. 212-219.

${ }^{24}$ Véase Frances Power Conne, Life of Frances Power Cobbe, 2 vols., la reacción de Darwin ante la publicación de The Subjection of Women de John Stuart Mill. 
animales y los seres humanos, Darwin apoyó con todo el prestigio de su nombre estas ideas. La teoría de la evolución de Darwin suponía que la naturaleza se construye continuamente. Darwin postulaba que los seres humanos y otros organismos complejos habian evolucionado a lo largo de enormes periodos de tiempo, a partir de formas de vida menos complejas, es decir, surgían y se complejizaban constantemente. Así, la escala de la naturaleza no era algo fijo, sino que estaba en proceso de ser, como resultado de la evolución de las formas de vida. Se entendía que la noción darwiniana de complejidad significaba grado de perfección, de modo que, cuanto más complejo era un organismo, más perfecto era. Darwin y los posdarwinistas comenzaron a hablar de especies "superiores" e "inferiores" de modo que conllevaban claros juicios de valor sobre su perfección.

La enorme cantidad de informes que sobre distintas razas y culturas de lejanos países proporcionaban viajeros, comerciantes, misioneros o etnólogos hizo que los científicos se preguntaran: ¿son los seres humanos una o muchas especies? ¿Eran semejantes los seres humanos bajo la piel o, por el contrario, los distintos grupos de seres humanos habian sido creados como especies diferentes? La tradición antropológica del siglo XVIII tendía al monogenismo debido a que su compromiso con una historia universal de la evolución cultural requería el supuesto de una unicidad humana. Por su parte, la etnologia del siglo xIX, en cierto modo madre de la antropologia, estaba más preocupada por la diversidad cultural que por la biológica; y aunque estaba convencida de la superioridad de la raza "europea", lo atribuían al entorno, no a la biología: las razas eran resultado de la diversidad medioambiental y, en principio, su situación podía ser remediada.

Desde el darwinismo también se postulaba la creencia en la unicidad y en la continuidad, en que no habría saltos en la escala de perfección. "Todo el abismo de la Naturaleza, desde una Planta al Hombre, está lleno de diversas Clases de Criaturas, surgiendo una de otra, mediante tan gentil y fácil ascendiente, que las pequeñas Transacciones y Desviaciones de una Especie a otra son casi insensibies". ${ }^{25}$ Como no podía haber vacio entre los monos y el hombre, la hipótesis de la continuidad requería que hubiera muchos grados de perfección dentro de la especie humana. Según se descubrian culturas supuestamente "primitivas", los evolucionistas aceptaban que el abismo percibido entre estas sociedades y las de Europa, mostraba que los pueblos "primitivos" se hallaban en la escala por encima de los monos pero debajo de los humanos "civilizados". Georges Pouchet, antropólogo francés del siglo diecinueve, escribió que "no faltan ejemplos de razas situadas tan abajo, que parecen de forma natural asemejarse a la tribu de los monos. Estos pue-

${ }^{25}$ Joseph Addison, The Spectator, núm. 519. 
blos, mucho más cercanos que nosotros al estado de naturaleza, merecen por eso toda la atención por parte del antropólogo". ${ }^{26} \mathrm{Y}$ en esa escala, la mujer -naturaleza por encima de todo- no estaba en el mismo escalón que el hombre.

Darwin se ocupa de la naturaleza de la mujer en su obra The Descent of Man and Selection in Relation to Sex. El tema principal de este texto es el fenómeno de la selección sexual, que había definido en On the Origin of Species.

Esta forma de selección depende, no de la lucha por la existencia en relación con otros seres orgánicos ni de condiciones externas, sino de la lucha entre los individuos de un sexo, generalmente los machos, por poseer al otro sexo. El resultado no es la muerte del competidor que no tiene éxito, sino poca o ninguna descendencia. Por consiguiente, la selección sexual es menos estricta que la selección natural. Por lo general, los machos más vigorosos, los más adecuados a su lugar en la naturaleza, dejarán más progenie. Pero en muchos casos, la victoria no depende tanto del vigor general, como de que se tengan armas especiales, que se limitan al sexo masculino. ${ }^{27}$

La selección sexual, a diferencia de la selección natural, sólo se da entre miembros de la misma especie: "Depende de la ventaja que ciertos individuos tienen sobre otros del mismo sexo y especie solamente con respecto a la reproducción. ${ }^{28}$

Así, Darwin postulaba un segundo mecanismo evolutivo, además de la selección natural. Afirmaba que algunas estructuras $e$ instintos se desarrollan como resultado de la capacidad para atraer al sexo opuesto. Entre éstos se hallaban incluidos el coraje masculino y la belicosidad, las armas de ofensa y defensa que permite que los machos luchen y ahuyenten a los rivales, y los ornamentos de los machos, tales como plumaje, voz y olores que sirven para atraer y excitar a las hembras. Darwin mantenía que esas estructuras no podian ser resultado de la selección natural, "ya que los machos sin armas, ornamentos ni atractivo, tendrían igualmente éxito en la lucha por la vida y en dejar numerosa progenie, si no fuera por la presencia de machos mejor dotados".29

${ }^{26}$ Pouchet, The Plurality of the Human Race, p. 16.

${ }^{27}$ Charles Darwin, On the Origin of Species. 7a. ed. Nueva York, Collier and Son, 1909, p. 108.

${ }^{28}$ C. Darwin, The Descent of Man and Selection in Relation to Sex. AMS Press, 1972, p. 276.

${ }^{29}$ Ibid., p. 279. 
Pero en la selección sexual hay un importante componente adicional: son las hembras las que eligen y los ornamentos de los machos se desarrollan porque a las hembras les atraen más los machos de apariencia extraordinaria: "Las hembras se sienten más excitadas, o prefieren aparearse con machos más ornamentados, los que cantan mejor o hacen las mejores gracias"; sin embargo, Darwin no podia dejar en manos de las hembras -léase "de las mujeres"- este importante factor evolutivo, por lo que, más adelante, afirma: "es probable que a la vez prefieran a los machos más vigorosos y vivaces". 30

Cuando examinamos las diferencias físicas y psicológicas entre la mujer y el hombre que según Darwin eran resultado de la selección sexual, encontramos que en cada caso los rasgos masculinos son los que generalmente se asocian con grados superiores de perfección. "Algunos autores dudan acerca de si hay [...] diferencias inherentes en las capacidades mentales de los sexos" Esa diferencia es, cuando menos "probable debido a la analogía de los animales inferiores que presentan otros caracteres sexuales secundarios". La analogía es uno de los recursos favoritos de Darwin en The Descent of Man. Y, además, utiliza el recurso retórico del ejemplo para apoyar sus tesis: quienes crian animales domésticos o poseen animales salvajes estarán de acuerdo con él en que "el toro difiere en disposición de la vaca, el jabalí de la jabalina, el semental de la yegua y también saben de sobra los que tienen casa de fieras, los machos de los monos grandes de las hembras". Darwin utiliza estos ejem. plos para ilustrar sus ideas sobre las mujeres y los hombres; pero no se queda en la simple analogía, pues pasa a afirmar un auténtico compendio de características que constituyen los estereotipos socioculturales de los hombres y mujeres victorianos: aquellos superan a las mujeres en coraje, energía y agresividad, y en las facultades intelectuales de abstracción, razón e imaginación. Las mujeres son más intuitivas, de percepción más rápida y más imitativas. Pero su evidencia empírica se queda en meros "es probable", "parecen diferir", "posiblemente", "difieren en disposición", etcétera. "Por término medio, el hombre es más alto, más pesado y más fuerte que la mujer, tiene hombros más cuadrados y músculos más completamente pronunciados [...] El hombre tiene más coraje, es más belicoso y enérgico que la mujer y tiene un genio más inventivo". ${ }^{31}$ Las características femeninas están asociadas, claramente, con estados menos evolucionados, más imperfectos e inferiores. "La hembra [...] se dice que la formación de su esqueleto está entre el niño y el hombre". ${ }^{32}$ "Se admite por lo general que en las mujeres están más fuertemente marcados que en los hombres los poderes de intuición, percepción

${ }^{30}$ Ibid., p. 283.

${ }^{31}$ Ibid., pp. 716-717. Subrayados míos.

32 Ibid., p. 717. 
rápida y quizás de imitación; pero al menos algunas de estas facultades son características de las razas inferiores y, por tanto, de un estado pasado e inferior de civilización". ${ }^{33}$ Aquí el sexismo de la teoría de Darwin se mezcla con su racismo. Darwin concebía las razas del "hombre" dispuestas jerárquicamente desde las más primitivas e inferiores a las más perfectas -no sorprendentemente las razas europeas civilizadas. Dentro de cada raza, se consideraba que la mujer estaba en un estadio inferior de perfección que el varón de la misma raza. Esto permitía que algunas mujeres, a saber, las europeas, blan. cas y de clases elevadas, se consideraran más evolucionadas que algunos varones, tales como los africanos, negros, dentro del principio general de que la mujer está menos evolucionada que el hombre.

Además de la selección sexual, Darwin mantenía que también era posible una mayor variabilidad y complejidad de los machos gracias a su papel en la procreación. Darwin se hizo eco de la tradición aristotélica al insistir en que la mujer debe gastar gran parte de su energía en alimentar al feto, afirmando que este gasto de energia impide la variación femenina. El macho, al necesitar sólo una pequeña cantidad de energía para formar su semilla y al no desempeñar papel alguno en el desarrollo del feto, dispone de una reserva de energía para su propio desarrollo. Y más adelante dice: "La mujer tiene que gastar mucha materia orgánica en la formación de sus óvulos, mientras que el macho gasta más fuerza en contiendas fieras con sus rivales, en vagar en busca de la hembra, en ejercitar su voz, emitir secreciones olorosas, etcétera".$^{34}$ Efectivamente, la teoria del instinto que Charles Darwin presentaba en The Descent of Man apoyaba la diferencia intelectual entre hombres y mujeres y justificaba su confinamiento en la esfera privada: el instinto mater. nal hace que las mujeres sean más tiernas y cariñosas y menos egoístas; por ese motivo, quienes se oponían al movimiento en favor de los derechos de las mujeres decían que ese instinto maternal era estupendo para la esfera privada, pero no asi para la pública, pues iría en contra del desarrollo evolutivo de la sociedad: el instinto maternal haría que se fuera indulgente con quienes, según la teoría de la evolución social, deberían desaparecer, ya que sólo sobreviven los más adecuados. ${ }^{35}$ Una vez más, afirmaciones dudosas,

${ }^{33}$ Ibid., pp. 725-726. Subrayados míos.

${ }^{34}$ Ibid., pp. 295-296.

${ }^{35}$ Véase el artículo citado en la bibliografía de $\mathbf{H}$. Spencer. Mas los que apoyaban los derechos de la mujer también usaron la teoría darwinista para decir que, si los instin. tos de las mujeres hacian que éstas fueran más cuidadosas y cariñosas, su intervención en la esfera pública provocaría un mayor bienestar social y menores conflictos bélicos (véase J. Addams, Peace and Bread in Time of War. Nueva York, Macmillan, 1922). 
pero que se repiten una y otra vez para "hacerlas" verdaderas, se esgrimen para mantener y justificar ciertas situaciones sociales. ${ }^{36}$

La definición de las diferencias sexuales como explicación de las diferencias de género también fue un interés primordial de la antropología física del siglo xIx. Nacida de la anatomía, la zoología y la medicina, aunque su preocupación principal era la diversidad humana, la antropología establecía una analogía entre negros y mujeres: "las mujeres son, en algunos aspectos, tan inferiores a los hombres como los negros a los europeos [...] debido a su maduración y decadencia más rápidas y a su desarrollo imperfecto" $"{ }^{37}$ Estamos aquí en un círculo vicioso semejante al que se daba en Aristóteles: las mujeres son inferiores porque, entre otras cosas, son imperfectas; y son imperfectas porque no son hombres; y no son hombres porque son inferiores. Además, por las manifestaciones de los antropólogos mismos, está claro que hay razones diferentes a los datos "objetivos" y "neutros" que llevan a defender y justificar como inferiores a las mujeres; Paul Broca advertía de que, cualquier cambio en el orden social y sexual del siglo XIx "induciría necesariamente una perturbación en la evolución de las razas y de ahí se sigue que la condición de la mujer en la sociedad debe ser cuidadosamente estudiada por el antropólogo". Al igual que "el carácter inferior del negro" sancionaba la esclavitud o el colonialismo, el de la mujer sancionaba su "sometimiento"

La idea principal que regia la antropología de este periodo consistía en buscar indices o datos empiricos de las diferencias de "temperamento" o "inteligencia". Para ello, los antropólogos se centraron en tres aspectos, los anatómicos, los fisiológicos y los craneales. Los datos de este tipo sobre diferencias sexuales se habian ido acumulando desde 1860, y en 1894, Havelock Ellis, publicó un resumen de la opinión consensuada, científica y médica de la época.

Las mujeres, mantenía, eran por lo general más parecidas anatómicamente a los niños que los hombres. Eran más bajas y ligeras por término medio, pero en relación con su altura total, las mujeres tenían la cabeza más gran de, cuellos más cortos, troncos más largos y miembros más cortos que los hombres. Algunos fisiólogos y anatomistas ${ }^{38}$ mantenían que tener troncos cortos era típico de las razas superiores, pero Ellis no estaba de acuerdo

${ }^{36}$ De hecho, este es aún el argumento de los sociobiólogos contemporáneos. Véase, por ejemplo, los escritos de Wilon, Sociobiology: The New Synthesis, Barash, The Whisperings Within, y Dawkins, The Selfish Gene. Como muestra de los debates que han surgido alrededor de la ciencia de la sociobiologia, véase Caplan, The Sociobiological Debate, Ruse, Sociobiology: Sense or Nonsense? y Lewontin et al., Not in Our Genes.

${ }^{37}$ Observaciones de T. Bendyshe al articulo de James Hunt, "On the Negro's Place in Nature", en Anthropological Review, núm. 2, 1864, pp. xxxvi-xxxvII.

${ }^{38}$ Ellis cita al fisiólogo alemán J. Ranke. 
porque los negros, que claramente eran inferiores según él, eran quienes tenían los troncos más cortos. Por lo que se refiere a la cortedad de miembros de las mujeres, eso indicaba su carácter infantil; pero Ellis no estaba de acuerdo en considerar que eso fuera indicio de salvajismo o semejanza a los simios; si lo hubiera hecho, se habria encontrado con una contradicción, pues los negros tenían los miembros más largos, según indicaban los numerosos estudios antropométricos que se habían realizado durante la guerra civil norteamericana. ${ }^{39}$

Donde se aprecia muy bien la reconstrucción retórica del sexo es en lo que se llamaba el "gran hecho fisiológico de la existencia de la mujer", la menstruación. Este solo hecho fisiológico sirve para explicar que la mujer no pueda aspirar a la igualdad profesional y social con el hombre. Según los científicos de la época, la menstruación es una maldición original, no un proceso natural. Desde luego, no hay duda del trasfondo social e ideológico que hay tras esa idea, pues, como observaba la médico americana Mary Putnam Jacobi a la hora de evaluar los aparatos reproductivos de varones y hembras se usaba un doble estándar: mientras en aquéllos era una fuente de poder, en las mujeres era un hecho patológico que quitaba valor a la salud o a las actividades normales. ${ }^{40}$ Las mujeres victorianas llevaban vestidos pesados y molestos con ajustados corsés, 'apenas hacían ejercicio, ignoraban por lo general su fisiología y pertenecían a una cultura que las consideraba inválidas, lo que, sin duda alguna debía aumentar su malestar fisico. Sin embargo, se consideraba que esa maldición se debía a que la mujer se acerca más que el hombre al tipo animal "si es cierto que [la descarga menstrual] también es característica de las monas antropoides y otras hembras mamiferas". En efecto, durante la menstruación "las mujeres sufren languidez y depresión que las incapacita para pensar o actuar y hace sumamente dudoso hasta qué punto pueden ser consideradas seres responsables mientras dura la crisis". 41 Y dice aún:

Aunque las mujeres poseyeran un cerebro igual al de los hombres -si las capacidades intelectuales de ellas fueran iguales que las de ellosla eterna distinción en la organización física de los sexos haría que, a

39) Man and woman, pp. 53.54.

40 Mary Putnam Jacobi. The Question of Rest for Women During Menstruation. Nueva York, 1886. Reimpreso en Dabor Social Science Pub., 1978. Debemos recordar aquí cómo a lo largo de la historia se ha "definido" con diferentes criterios a hombres y mujeres: mientras a aquéllos se les define sociopolíticamente, a las mujeres se las define biológicamente. Claro que esta definición biológica como se ve no es tal.

${ }^{41}$ No hace mucho, en el Parlamento británico, un célebre diputado laborista atribuía a la menstruación la actuación de la señora Thatcher durante la guerra de las Malvinas. 
la larga, el hombre medio fuera superior mentalmente a la mujer media. En el trabajo intelectual el hombre ha sobrepasado, sobrepasa y siempre lo hará a la mujer, por la evidente razón de que la naturaleza no interrumpe periódicamente su pensamiento y aplicación. ${ }^{42}$

Es decir, la menstruación es un obstáculo insuperable para que la mujer acceda al dominio intelectual, porque todas tienen comportamientos extraños en ese periodo. Se utiliza el ejemplo de mujeres que sufren depresión y languidez durante la menstruación para hacer una inducción retórica en la que se ve lo universal en un caso particular. Este es, por cierto, un recurso ya identificado y expuesto por Aristóteles en su Retorica y que debe quedar excluido de la verdadera ciencia. ${ }^{43}$ Además, aparece una afirmación no justificada, la de que la menstruación interrumpe el pensamiento, sin olvidarnos que se da por sentado lo que se quiere probar, a saber, que el hombre es, ha sido y será, superior intelectualmente a la mujer, por lo que el papel de ésta en la sociedad ha de ser subordinado.

Hoy en día la ciencia ya no posee el prestigio de hace unas décadas, pero se sigue apelando a ella en el debate sobre la desigualdad sexual. Y mediante ella se nos intenta convencer, se nos intenta persuadir de que lo que es "género" es "sexo". En nuestra ćpoca, las opiniones y tesis que acabamos de comentar han adquirido otro carácter. La reformulación de la teoría evolutiva que supone la sociobiologia, la neurología y la endocrinologia se han utilizado indistintamente para remitir las diferencias intelectuales y sociales a diferencias biológicas de esos tres tipos. Para los sociobiólogos, el principal motor de la evolución es el gen egoísta, ${ }^{44}$ que maximiza su éxito reproductivo y la información genética que transmite de una generación a la siguiente. Como la mujer embarazada invierte mucho en el desarrollo del embrión, alcanzará mayor éxito reproductivo de sus propios genes si invierte tiempo y esfuerzo en la cría de su prole, una vez nacida. Miles de años de historia evolutiva harían que las mujeres estuvieran mejor adaptadas para la cria de la progenie $y$, por consiguiente, el hecho de que esté desigualmente repartido el trabajo del cuidado de los hijos entre hombres y mujeres estaria genéticamente determinado y, se concluye, seria irreversible. El paso de la "biología" a la "sociología del trabajo" es claro.

${ }^{42} \mathrm{~J}$. McGrigor Allan, "On the Real Differences in the Minds of Men and Women", en Journal of the Anthropological Society of London, núm. 7, 1869, p. CCXII.

43. También podríamos llamarle el principio de corresponsabilidad del sexo femenino; esto es, si un varón hace algo mal, es él individualmente, Fulanito, quien lo ha hecho. Pero si es una mujer, todas sus congéneres son corresponsables.

${ }^{44}$ R. Dawkins, The Selfish Gene. Nueva York, Oxford University, 1976; trad. esp. El gen egoísta. Ed. Labor. 
También, la investigación neurológica sugiere que los cerebros de hombres y mujeres difieren estructuralmente desde antes del nacimiento. Tales diferencias darían cuenta de "hechos" tales como el que las mujeres ven mejor por la noche, mientras los hombres ven mejor durante el día, que las mujeres tienen mejor sentido del olfato, mejor oído tonal y tienen menos sueños de contenido sexual; pero también darían cuenta, por ejemplo, de presuntas diferencias como las capacidades espaciales y lingüísticas: mientras las mujeres procesan la información espacio-visual y verbal con ambos hemisferios cerebrales, parece que los hombres procesan la información verbal con el hemisferio izquierdo y la espacial con el derecho. Al margen de lo dudosa que resulta la universalidad de los primeros "hechos" aludidos y de la obtención de resultados contradictorios con respecto a ellos, ${ }^{45}$ lo curioso es que se utilice el resultado de esas investigaciones para afirmar que las mujeres están mejor preparadas que los hombres para cuidar a los niños, en especial para enseñarles a hablar, en vez de sugerir que se dediquen a actividades en las que la capacidad verbal sea importante, como, por ejem. plo, la política, la judicatura o los negocios.

Argumentos semejantes se han manejado desde la endocrinología, con un barniz supuestamente más objetivo. Una y otra vez se afirma que las hormonas femeninas hacen que las mujeres sean más "sensibles" a los niños que los hombres y, por lo tanto, que estén mejor adaptadas a la maternidad. Las hormonas masculinas harian más agresivos a los hombres, lo que les convertiria en más aptos para la terrible lucha que se da en el mundo laboral. Por consiguiente las mujeres no sólo "no deben buscar igual participa. ción en el trabajo que los hombres", ${ }^{46}$ sino que una lucha semejante está abocada irremediablemente al fracaso, sería inútil. Pero, ¿qué sucede con las mujeres agresivas? ¿Es que tienen hormonas masculinas del mismo modo que las mujeres ingeniosas y hábiles poseían calor y sequedad, es decir, cualidades masculinas, como decia Huarte de San Juan? ¿Qué hay de los hombres sensibles? Sin dejar de lado que esas mismas tesis pueden ser utilizadas en favor de lineas de actuación diferentes: si esas afirmaciones fueran ciertas, habría que alentar la participación de las mujeres en la vida pública, pues esos atributos, ya estén hormonal o socialmente determinados, enriquecerían la vida pública y promoverían las causas pacifistas y progresistas.

Como se aprecia en este breve panorama, se pueden aducir tesis biológicas en un sentido y en otro. Podemos darnos cuenta de que lo característico

\footnotetext{
45 Sobre los logros de la endocrinología y la neurología con respecto a las diferencias sexuales véase el excelente estudio de Anne Fausto-Sterling, 1992, especialmente el capítulo 8, Longino, 1990, capítulos 6 y 7 y Longino y Doell, 1983.

${ }^{46}$ A. Rossi, 1977, p. 25.
} 
de todas las tesis deterministas que se mantienen en estas discusiones es la ausencia de justificación biológica de las diferencias intelectuales. Las desigualdades socioculturales y politicas se pretenden inferir de supuestas observaciones de "hechos biológicos": neurológicas, hormonales, etcétera. Sin embargo, no podemos encontrar por ninguna parte el nexo lógico entre estos "hechos" y aquellas diferencias; ${ }^{47} \mathrm{y}$ aun asi se repiten tales afirmaciones hasta la saciedad: lo que se dice tres veces es verdadero. ${ }^{48}$ En realidad, se nos presentan teorias que bajo el barniz biológico, de lo "natural", de lo neutral y objetivo, esconden un enmascaramiento de cuestiones de género, es decir, contextuales o externas. La retórica de la ciencia ha sido, una vez más, sumamente eficaz al convencer, al persuadir, de que unas características socioculturales son naturales, biológicas y que éstas deben determinar el papel que las mujeres deben desempeñar en la sociedad.

${ }^{47}$ Las mujeres no son el único caso, por supuesto. Algunos trabajos "científicos" sobre razas u homosexuales adolecen de los mismos defectos.

${ }^{48}$ Como en La caza del snark de Lewis Carroll. Véase E. Pérez Sedeño, "La sìndrome de l'Snark i altres històries: ficció o realitat?", en Quaderns, núm. 1, Barcelona, 1995. 